\title{
Ex vivo evaluation of a prototype submucosal biopsy forceps for the diagnosis of gastric gastrointestinal stromal tumors
}

\author{
Jeffrey Laczek ${ }^{1}$, Nader Hanna ${ }^{2}$, William Twaddell ${ }^{3}$, Peter Darwin ${ }^{1}$ \\ ${ }^{1}$ Department of Gastroenterology, University of Maryland Medical Center, Baltimore, USA \\ ${ }^{2}$ Department of Surgical Oncology, University of Maryland Medical Center, Baltimore, USA \\ ${ }^{3}$ Department of Pathology, University of Maryland Medical Center, Baltimore, USA \\ Email: jlaczek@hotmail.com
}

Received 20 September 2012; revised 25 October 2012; accepted 7 November 2012

\begin{abstract}
Gastrointestinal stromal tumors (GISTs) account for approximately $2 \%$ of gastric cancers and can be challenging to diagnose due to the difficulty sampling tissue from these lesions. Current biopsy methods are inadequate for determining the mitotic index, a major prognostic factor of these tumors. We sought to evaluate the ability of a prototype submucosal biopsy forceps to make a histologic diagnosis and mitotic index determination in cases of resected gastric GISTs. After obtaining informed consent and surgical resection of three gastric GISTs, an investigational submucosal biopsy forceps and sheath was passed under direct visualization into the central portion of the tumors (in the ex vivo setting) and biopsies were obtained. The tumor was then processed for standard histology. A gastrointestinal pathologist, blinded to the mitotic index of the full specimen, evaluated the research biopsies. The results from the submucosal forceps biopsies were then compared with the standard histology results. In all 3 cases, the submucosal forceps biopsies confirmed the diagnosis of a GIST. In two out of three cases, the submucosal forceps biopsies accurately classified the risk for progressive disease (based on the mitotic index) when compared to standard histology. In one case, the research biopsy mitotic index would have resulted in an underestimation of tumor risk (biopsies categorized the lesion as "very low" rather than "moderate" risk).
\end{abstract}

Keywords: Gastrointestinal Stromal Tumor; GIST; Biopsy; Submucosal

\section{INTRODUCTION}

Gastrointestinal stromal tumors (GISTs) account for approximately $2 \%$ of gastric cancers [1] and can be chal- lenging to diagnose due to the difficulty sampling tissue from these lesions [2]. There is no consensus on the management of these lesions, particularly when they are small or asymptomatic [3]. Current biopsy methods are inadequate for determining the mitotic index, a major prognostic factor of these tumors [4]. We sought to evaluate the ability of a prototype submucosal biopsy forceps to make a histologic diagnosis and mitotic index determination in cases of resected gastric GISTs.

\section{METHODS}

After obtaining informed consent and surgical resection of three gastric GISTs, an investigational submucosal biopsy forceps and sheath (Figures 1 and 2, Olympus America XB01-998-5/6—not commercially available, not 501 cleared) was passed under direct visualization into the central portion of the tumors (in the ex vivo setting) and biopsies were obtained. The sheath served to protect the working channel of the endoscope from the forceps. The forceps themselves pierced the tumor with minimal resistance and were then operated similar to conventional forceps. The size of the biopsies was small

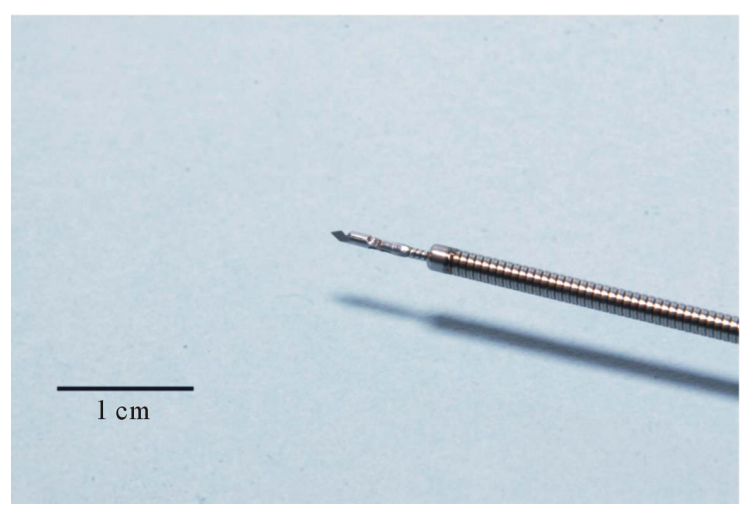

Figure 1. Submucosal biopsy forceps and sheath (forceps in the closed position). 


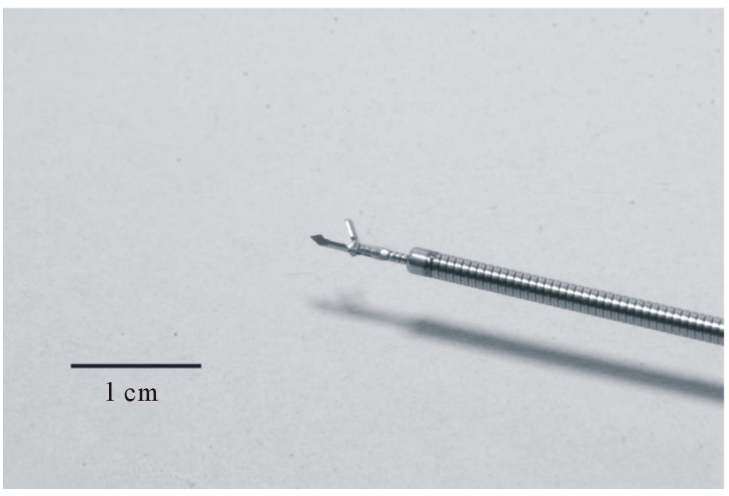

Figure 2. Submucosal biopsy forceps and sheath (forceps in the open position).

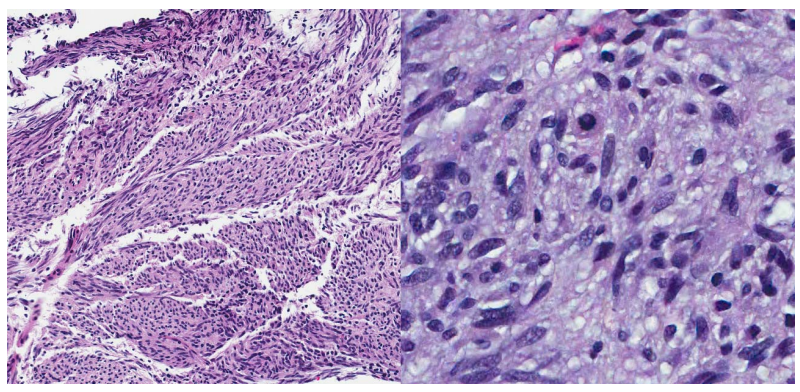

Figure 3. Photomicrographs of a biopsy specimen obtained with the submucosal biopsy forceps. Left is low power $(100 \times)$ showing a spindle cell morphology consistent with a GIST. Right is high power $(400 \times)$, used to allow for an assessment of the mitotic index.

Table 1. Submucosal biopsy forceps results compared with final histology.

\begin{tabular}{llllll}
\hline & $\begin{array}{l}\text { Histologic confirmation } \\
\text { of GIST? }\end{array}$ & $\begin{array}{l}\text { Biopsy mitotic } \\
\text { index }^{\mathrm{a}}\end{array}$ & $\begin{array}{l}\text { Risk for progressive } \\
\text { disease based on biopsy }\end{array}$ & $\begin{array}{l}\text { Final histology } \\
\text { mitotic index }^{\mathrm{a}}\end{array}$ & $\begin{array}{l}\text { Risk for progressive disease } \\
\text { based on final histology }^{\mathrm{b}}\end{array}$ \\
\hline Sample 1 & Yes & 2 & Very low & 7 & Moderate \\
Sample 2 & Yes & 2 & Very low & 3 & Very low \\
Sample 3 & Yes & 6 & Moderate & 6 & Moderate \\
\hline
\end{tabular}

${ }^{\mathrm{a}}$ Mitoses per 50 high-power fields; ${ }^{\mathrm{b}}$ The risk for recurrence or progression of GISTs is related to their location (stomach, duodenum, jejunum/ileum, or rectum), size, and mitotic index (the number of mitoses per 50 high-power fields).

compared with biopsies obtained by conventional forceps.

The tumor was then was then processed for standard histology. A gastrointestinal pathologist, blinded to the mitotic index of the full specimen, evaluated the research biopsies. The results from the submucosal forceps biopsies (Figure 3) were then compared with the results of standard histology.

\section{RESULTS}

In all three cases, the submucosal biopsy forceps biopsies confirmed the diagnosis of a GIST. The estimated mitotic index (mitoses per 50 high-power fields) from the submucosal forceps biopsies, as well as the final histology results, are shown in Table 1. The submucosal forceps biopsy mitotic index would have resulted in an underestimation of the tumor risk in one case (biopsies categorized the lesion as "very low" rather than "moderate" risk) [4,5].

\section{CONCLUSION}

In the ex vivo setting, this novel submucosal biopsy forceps was able to provide a tissue diagnosis for all three GISTs; it provided an accurate mitotic index in 2 out of 3 cases. The small size of the biopsies is a limitation of this technique. Future studies are needed to evaluate the safety of this device in vivo.

\section{ACKNOWLEDGEMENTS}

Funded by the Ellen Schumer Memorial Fund.

\section{REFERENCES}

[1] Thomas, R.M. and Sobin, L.H. (1995) Gastrointestinal cancer. Cancer, 75, 154-170. doi:10.1002/1097-0142(19950101)75:1+<154::AID-CNC R2820751305>3.0.CO;2-Z

[2] Hoda, K.M., Rodriguez, S.A. and Faigel, D.O. (2009) EUS-guided sampling of suspected GI stromal tumors. Gastrointestinal Endoscopy, 69, 1218-1223. doi:10.1016/j.gie.2008.09.045 PMid:19394006

[3] Ryu, K., Jung, S., Choi, J., Jang, Y., Kim, J., Park, S., Park, B.J., Park, S., Kim, S., Mok, Y. and Kim, C. (2011) Laparoscopic resection of small gastric submucosal tumor. Surgical Endoscopy, 25, 271-277. doi:10.1007/s00464-010-1173-0

[4] Demetri, G.D., von Mehren, M., Antonescu, C.R., DeMatteo, R.P., Ganjoo, K.N., Maki, R.G., Pisters, P.W., Raut, C.P., Riedel, R.F., Schuetze, S., Sundar, H.M., Trent, J.C. and Wayne, J.D. (2010) NCCN task force report: Update of the management of patients with gastrointestinal stomal tumors. Journal of the National Comprehensive Cancer Network, 2, S1-S41. 
[5] Miettinen, M. and Lasota, J. (2006) Gastrointestinal stromal tumors: Pathology and prognosis at different sites.
Seminars in Diagnostic Pathology, 23, 70-83. doi:10.1053/j.semdp.2006.09.001 PMid:17193820 